\title{
17
}

\section{Mediación cultural para todos los públicos}

\author{
Charo Ramos \\ Periodista
}

Ataviados con batas blancas, sentados frente a una pantalla, una veintena de estudiantes de Primaria observa atentamente un vídeo donde se habla de insectos xilófagos, pérdida cromática, barnices. Inés y Gracia, restauradoras de profesión y pedagogas de vocación, acercan a estos escolares inquietos una de las experiencias más hermosas e intransferibles: la contemplación de la belleza y de los secretos que la sustentan.

Están visionando un documental donde se desglosa la intervención por el Instituto Andaluz del Patrimonio Histórico (IAPH) de una obra maestra de Murillo: Santa Isabel de Hungría curando a los tiñosos. Los alumnos aún no saben qué padecimientos conlleva esa enfermedad llamada tiña y apenas recuerdan que este cuadro procede del Hospital de la Caridad de Sevilla, donde alguno ha podido verlo ya restaurado. Pero en este taller didáctico enmarcado en la conmemoración del Año Murillo han aprendido tantos secretos del artista y de su obrador, como el lapislázuli que empleaba en los mantos de las Inmaculadas, que ya nada será igual cuando vuelvan a visitar el templo.

Un aspecto llamativo es que el mismo material didáctico, un vídeo, resulte de tanta utilidad para los escolares de Primaria y Secundaria como para un profesional de un medio de comunicación: este acervo de información avalado por los expertos del IAPH permite elaborar un relato de distintos niveles y para diferentes audiencias, acercando unas conclusiones científicas que en su día dio a conocer la revista $\mathrm{PH}$ y que son accesibles a través de la página web de la institución.
Desde que Andalucía pudo poner en marcha sus propias políticas culturales, en desarrollo de la Constitución de 1978, la iniciativa pública ha ido creando una red de protección y tutela del patrimonio que constituye un pilar de nuestro sistema cultural. Esas políticas patrimoniales, que han generado un repertorio de servicios y una trama normativa, extendieron su ámbito de influencia con el apoyo decisivo de los medios de comunicación social.

En las hemerotecas, pero también en internet y en las redes sociales, habita la memoria de la gestión patrimonial de los últimos 25 años. Y las palabras clave que etiquetan las informaciones para su consumo digital no dejan lugar a duda: las restauraciones, publicaciones, presentaciones y visitas guiadas han ido ocupando el lugar que hasta hace poco monopolizaron expolios, derribos, abandonos y pillajes, con excepciones aún funestas como el patrimonio subacuático sustraído por la empresa Odyssey.

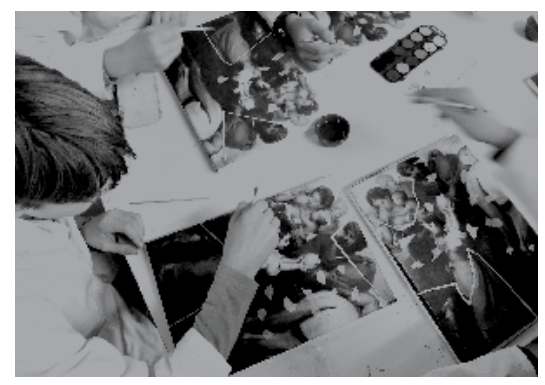

Escolares en un taller pedagógico del IAPH con motivo del Año Murillo. Foto Juan Carlos Vázquez 
Con la creación en 1989 del IAPH, Andalucía se dotó de una institución que, además de salvaguardar y proteger su legado material e inmaterial, desarrolla una labor documental que permite acceder a la ciudadanía al conjunto estructurado de datos de los bienes culturales de la Comunidad. La información que el IAPH ofrece, por su versatilidad y rigor, ha ayudado a identificar, proteger y divulgar los recursos culturales de Andalucía. Con su presencia pionera en las redes sociales, ha creado además una comunidad de usuarios que se relaciona activamente a través de la página web de la institución.

Al calor de la revolución digital, los periodistas estamos asistiendo, con estupor y preocupación, a una rebaja de la calidad de los contenidos que ha puesto en jaque la prensa que veníamos conociendo. La obsesión por captar usuarios a los que ofrecer experiencias, en vez de fidelizar a los lectores que exigen una información especializada con agenda propia, está haciendo tambalear los cimientos del periodismo cultural en todo el mundo.

Mientras se redefine el modelo por el que la prensa independiente sobrevivirá en el nuevo enjambre digital (suscripciones, muros de pago...), urge apoyar el periodismo de contexto, también llamado de segunda velocidad, como réplica a estos tiempos de fake news y clickbait. En este nuevo escenario, una publicación digital accesible y de servicio público como la revista $\mathrm{PH}$ cobra un especial relieve.

\section{"Los profesionales de los medios necesitan tejer una red de complicidades en su labor diaria y una alianza clave pasa por mantener como fuentes a los referentes intelectuales de las diversas disciplinas. PH lleva años erigiéndose como altavoz y baluarte de estas reflexiones, alentando debates que los medios debemos seguir trasladando a la sociedad"}

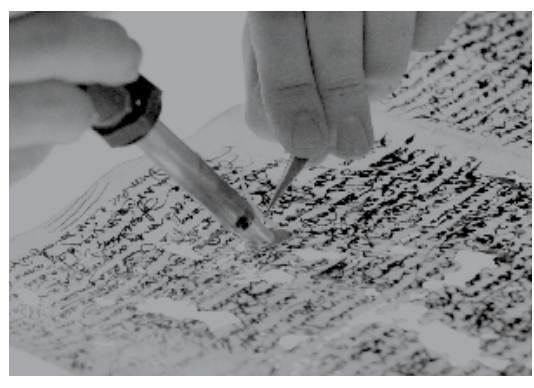

Restauración de un manuscrito en el Taller de Papel del IAPH. Foto José Angel García

El compromiso con el patrimonio del IAPH no se mide solo en función de los bienes que restauran sus especialistas, sino atendiendo a otros muchos factores, como la difusión y la enseñanza de las ideas y prácticas que sustentan la labor de conservación. Los profesionales de los medios necesitan tejer una red de complicidades en su labor diaria y una alianza clave pasa por mantener como fuentes a los referentes intelectuales de las diversas disciplinas. PH lleva años erigiéndose como altavoz y baluarte de estas reflexiones, alentando debates que los medios debemos seguir trasladando a la sociedad.

Es tiempo de fortalecer espacios de diálogo como esta revista y de acercarlos a la sociedad. Incrementar su rol de recurso pedagógico en las enseñanzas medias; atraer a las páginas de revista $\mathrm{PH}$ las firmas de profesionales de otros contextos científicos y reforzar el intercambio de ideas y experiencias con fundaciones y centros de investigación extranjeros, como el Warburg o el Courtauld Institute, son algunas líneas de trabajo que pueden enriquecer su misión editorial y su mediación cultural en los próximos años. 